\title{
Competency development for military nursing: developing the competency framework for global health
}

\section{Huijuan Ma}

Army Medical University

\section{Zhen Cheng}

Army Medical University

Jing Tan

Army Medical University

Yu Luo ( $\nabla$ luoyuhlgl@tmmu.edu.cn )

Third Military Medical University https://orcid.org/0000-0002-3566-3766

\section{Research}

Keywords: competency framework, military nurse, Delphi

Posted Date: May 4th, 2021

DOI: https://doi.org/10.21203/rs.3.rs-468341/v1

License: (c) (i) This work is licensed under a Creative Commons Attribution 4.0 International License. Read Full License 


\section{Abstract}

Background As military nurses are required to maintain high level of clinical expertise and currency for short-notice deployments of global health missions, competency assessment and capability building is a basic paradigm of military nursing. However, research focusing on the competencies of military nurses is limited.

Methods: A two-phased procedure was implemented. In phase 1, the competency framework was developed by scoping review and crosschecking the common used competency framework of nurses. During phase 2, two rounds of a Delphi process were carried out and a penal of experts used a 5-point Likert scale to rate their level of agreement with the competency statement.

Results: Experts of military nursing and military medicine responded to the first round $(n=19)$, and the second round $(n=19)$. The final competency framework consisted of 67 competencies and was classified into five domains: clinical nursing knowledge and skills, military nursing knowledge and skills, professional ability, management ability, and comprehensive quality.

Conclusion: The competency framework developed in this study lays solid foundation for competencybased education of a competent nursing team to play a significant role in the global health.

\section{Background}

Competency is defined as a personal trait or set of habits that lead to more effective or superior job performance, and competencies can be used for translating strategy into job-related performance and individual behaviours [1-3]. Competency-based education (CBE) has been used in the graduate, postgraduate and continuing education to improve the education quality and teaching effect, which is an outcomes-based approach to design, implement, assess and evaluate education programs through a well defined framework of competencies [4]. Therefore, developing a competency framework could be considered as a key step toward CBE [5].

Military nurses are frequently deployed by the governments for global health [6]. Compared with civilian nurses, military nurses have dual roles, including role of clinical nurse and military personnel. They normally shoulder diverse responsibilities, including providing nursing care in hospital and being deployed to war and public emergencies at short notice [7]. During deployment, the working environment is often dynamic and demanding, and this pose challenge to military nurses. When transit from routine work in hospital to an uncertain environment and from deployment environment to informal family chores, they experienced professionally, physically, mentally and personally challenge [8]. Besides, military nurses normally play an important part in management and leadership positions, such as company commander, head nurse, executive officer [9]. Due to diverse responsibilities indicating comprehensive competencies, along with the competencies of civilian nurses, military nurses also should meet the requirements of providing care during military deployment. 
Several competency frameworks and assessment tools of nurses have been developed in past decades, such as, Nurse Competency Scale (NCS), Self Evaluated Core Competencies (SECC) Scale, Competence Inventory for Registered Nurses (CIRN) [10-12]. However, research focusing on the competencies of military nurses is limited. In UK military, the five pillars of advanced level practice within the military nursing care were adapted, including tactical military competence, management and leadership, education, research, advanced clinical practice [13]. In USA military, the Readiness Estimate and Deployability Index (READI) was developed to assess deployment readiness competencies [14]. As military nurses are required to maintain high level of clinical expertise and currency for short-notice deployments, competency assessment and capability building is a basic paradigm of military nursing. A set of competency will aid in CBE of military nurses, therefore, we conducted a Delphi study to develop a competency framework of military nurses in the Chinese context.

\section{Methods}

The Delphi method was used in this study, which is considered as an effective way to achieve consensus by a group of experts on a given topic [15-16]. A panel of experts was consulted electronically and asked to identify and prioritize competency statements specific to military nurses. In this study, consensus was achieved by the end of the twice round.

\subsection{Constructing the initial framework}

Due to military nurses play an important part in management and leadership position (Ross, 2010), a scoping review of studies focusing on competencies of military nurse managers was carried out[8]. A five-step procedure of scoping review proposed by Levac and his colleague was taken [17]. The search terms " military", "army", "air force", "navy", "warrior", "combat", "armed force", "defense", "nurse", "nursing", "head", "mid-level”, "manager", "leadership", "executive”, "leader", "competence”, "competency", and "competencies" were used to search from PubMed, CINAHL, EMBASE, PsycINFO, Cochrane Library and Chinese databases including CNKI and Wanfang. After following the PRISMA flow chart, a total of nine studies were included in this review. The competencies identified in the above nine studies were developed into a framework of military nurse manager's competencies and summarized into six domains, which included clinical expertise, role model, leadership competencies, human competencies, financial competencies, and deployment competencies.

After the scoping review of military nurse manager's competencies, a literature review of competency assessment tools for nurses was also carried out. NCS and CIRN were identified to cross check with the framework of military nurse manager's competencies in the above scoping review. The final framework of nurses in military hospitals was developed after several group meetings between the research group, which consisted of five domains and 76 statements.

\subsection{The Delphi process}

\subsubsection{Selection of expert}


A panel of experts was selected from military nursing and military medicine. The following inclusion criteria were used in this process: (1) bachelor degree or higher degree; (2) professional experience exceeding 10 years and engaged in the field of military nursing and medicine with a solid theoretical foundation; (3) consent to participate. Purposive sampling was taken to make sure that a national panel with diverse expertise. A list of 24 potential participants was prepared by the researchers. The target experts were contacted to know their willingness to participate in this study, and twenty experts who met the eligibility criteria consented.

\subsubsection{Data collection}

Each expert who was consent to participate in this study received the questionnaire. They were asked to give feedback within two weeks, and they would be reminded if they did not give feedback in the given time. After receiving all the feedback from the expert panel, the data collected would be analyzed to develop the questionnaire for the next round. When the consensus achieved among the panel, the data collection process would be stopped.

In the first round, the questionnaire the expert received included the demographic information questionnaire and the competency framework of 76 statements regarding to military nurses. The statement with less than $70 \%$ consensus rate were deleted from the framework. The suggestions collected in the first round were discussed among the research team, and were utilized to refine the framework. In the second round, the questionnaire containing the refined framework were sent to the expert panel.

\subsubsection{Data analysis}

Data analysis was performed with IBM SPSS Statistics for Windows 22.0. The following variables were included in this study: demographics, approval rate (the percentage of statement rated as 4 or 5 by 1 to 5 significance Likert scale), coefficient of variation (CV). The statement would be selected if the mean value of significance score was more than 3.5, the approve rate was more than 705 and CV was less than 0.25 .

\subsection{Ethical consideration}

The study protocol was submitted to the Medical Ethics Committee of Army Medical University in Chongqing, China. The research was approved by the Medical Ethics Committee and determined to be exempt. Prior to the Delphi process, the expert would receive the introduction of this study and the informed consent form. The Delphi study was carried out among the expert who singed the informed consent form under willingness.

\section{Results}

\subsection{The first round}

Initially, 20 experts consented to participate, of whom 19 (95\%) finished the questionnaire among the first round. The demographic characteristics are presented in Table 1. The expert panel were composed of 
military nursing managers, military nursing educators, military nurses, military doctors and military medical service educators, with mean of age and working years being 42.474 (8.475) and 22.211(10.644), respectively.

Table 1

Demographic characteristics of experts

\begin{tabular}{|c|c|c|c|}
\hline & Participants & Number & Percent \\
\hline \multirow[t]{3}{*}{ Qualification } & Bachelor & 9 & 47.37 \\
\hline & Master & 3 & 15.79 \\
\hline & Doctor & 7 & 36.84 \\
\hline \multirow[t]{3}{*}{ Professional title } & Middle & 3 & 63.16 \\
\hline & High & 12 & 15.79 \\
\hline & Senior & 4 & 21.05 \\
\hline \multirow[t]{3}{*}{ Working years } & $\leq 15$ & 6 & 36.84 \\
\hline & $16-25$ & 8 & 31.58 \\
\hline & $\geq 26$ & 6 & 31.58 \\
\hline \multirow[t]{5}{*}{ Profession } & Nursing management & 5 & 26.32 \\
\hline & Nursing education & 4 & 21.05 \\
\hline & Clinical Nursing & 6 & 31.58 \\
\hline & Clinical Medicine & 2 & 10.53 \\
\hline & Military medical service & 2 & 10.53 \\
\hline \multirow[t]{3}{*}{ Age } & $\leq 40$ & 11 & 57.89 \\
\hline & $41-50$ & 5 & 26.32 \\
\hline & $\geq 51$ & 3 & 15.79 \\
\hline
\end{tabular}

In round 1 , all the 76 competencies met the selection criteria. From the panel comments, six competencies were combined to three competencies in domain 3 , and one were moved from domain 3 to domain 5 after the above combination. In the meanwhile, three competencies were deleted because of duplicate. See Fig. 1.

\subsection{The second round}

The questionnaire consisting of 70 competencies, was sent to the 19 panel members who responded in the first round. All the panel members responded. In round 2, 67/70 competencies met the selection 
criteria. From the panel comments, three competencies were deleted because of duplicate. See Fig. 1.

The final framework of competencies for military nurses consisted of 67 items and five domains. These five domains were clinical nursing knowledge and skills, military nursing knowledge and skills, professional ability, management, and comprehensive quality (see Fig. 2). This framework can be used to develop nurses from novice to expert at hospital and during deployment. The final list of competencies and their ratings can be seen in Table 2 . 
Table 2

Final list of competencies and their ratings

Primary indicator

$(\mathrm{M} \pm \mathrm{S}, \mathrm{CV}$, Approval rate $\%)$

1. Clinical nursing knowledge and skills

$(5 \pm 0,0.00,100 \%)$
Secondary indicator

( $\mathrm{M} \pm \mathrm{S}, \mathrm{CV}$, Approval rate \%)

1.1 Fundamental nursing knowledge and skills

$(5 \pm 0,0.00,100 \%)$
Third indicator

( $M \pm S, C V$, Approval rate \%)

1.1.1 nursing procedure

$(4.63 \pm 0.597,0.13,95 \%)$

1.1.2 Fundamental nursing theoretical knowledge

$(4.89 \pm 0.459,0.09,95 \%)$

1.1.3 Fundamental nursing skills

$(4.95 \pm 0.229,0.05,100 \%)$

1.1.4 Basic life support

$(4.95 \pm 0.229,0.05,100 \%)$

1.1.5 Medical equipment

$(4.95 \pm 0.229,0.05,100 \%)$

1.1.6 Observation and physical assessment

$(4.84 \pm 0.375,0.08,100 \%)$

1.1.7 Infection prevention and control

$(4.53 \pm 0.612,0.14,95 \%)$

1.1.8 Nursing document

$(4.53 \pm 0.697,0.15,89 \%)$

1.2 Specialist nursing knowledge and skills

$(4.89 \pm 0.315,0.06,100 \%)$
1.2.1 Specialized nursing knowledge

$(4.89 \pm 0.315,0.06,100 \%)$

1.2.2 Specialized nursing skills

$(4.89 \pm 0.315,0.06,100 \%)$

1.2.3 Critical care

$(4.89 \pm 0.315,0.06,100 \%)$

1.2.4 Knowledge of common drugs and emergency medicine

$(4.95 \pm 0.229,0.05,100 \%)$ 
Primary indicator Secondary indicator

$(\mathrm{M} \pm \mathrm{S}, \mathrm{CV}$, Approval rate

$\%)$
( $M \pm S, C V$, Approval rate \%)

1.3 Regulations and patient safety

$(4.32 \pm 0.582,0.13,95 \%)$

2.1 Fundamental combat casualty care

$(4.95 \pm 0.229,0.05,100 \%)$
$(4.95 \pm 0.229$

$0.05,100 \%)$

2. Military nursing knowledge and skills

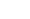

\section{Third indicator}

( $\mathrm{M} \pm \mathrm{S}, \mathrm{CV}$, Approval rate \%)

1.3.1 occupational safety protection regulations

$(4.63 \pm 0.496,0.11,100 \%)$

1.3.2 patient safety assessment and risk management

$(4.68 \pm 0.478,0.10,100 \%)$

1.3.3 work quality standard

$(4.68 \pm 0.478,0.10,100 \%)$

1.3.4 laws and regulations

$(4.42 \pm 0.607,0.14,95 \%)$

2.1.1 Casualty identification and assessment

$(4.63 \pm 0.496,0.11,100 \%)$

2.1.2 Fundamental combat casualty care skill

$(4.89 \pm 0.315,0.06,100 \%)$

2.1.3 Field transfusion and blood transfusion

$(4.84 \pm 0.375,0.08,100 \%)$

2.1.4 Puncture technique and cooperation

$(4.79 \pm 0.535,0.11,95 \%)$

2.2 Comprehensive combat casualty care

2.2.1 Different types of combat casualty care

$(4.89 \pm 0.315,0.06,100 \%)$

2.2.2 Different body parts of combat casualty care

$(4.89 \pm 0.315,0.06,100 \%)$

2.2.3 Combat casualty care of shock patients

$(4.89 \pm 0.315,0.06,100 \%)$ 
Primary indicator

$(\mathrm{M} \pm \mathrm{S}, \mathrm{CV}$, Approval rate

$\%)$
Secondary indicator

( $M \pm S, C V$, Approval rate \%)
Third indicator

( $\mathrm{M} \pm \mathrm{S}, \mathrm{CV}$, Approval rate \%)

2.2.4 Combat casualty care in special environment

$(4.74 \pm 0.452,0.10,100 \%)$

2.2.5 Combat casualty care of special weapon

$(4.53 \pm 0.513,0.11,100 \%)$

2.2.6 Care of the infectious disease wounded

$(4.89 \pm 0.315,0.06,100 \%)$

2.2.7 Care during evacuation and transit

$(4.79 \pm 0.419,0.09,100 \%)$

2.2.8 Nutrition support of the wounded

$(4.42 \pm 0.507,0.11,100 \%)$

2.2.9 Cooperation of field operation

$(4.53 \pm 0.513,0.11,100 \%)$

2.2.10 psychological intervention for the wounded

$(4.47 \pm 0.513,0.11,100 \%)$

2.2.11 Usage of field rescue backpack

$(4.37 \pm 0.597,0.14,95 \%)$

2.2.12 Nursing document writing during wartime

$(4.21 \pm 0.713,0.17,84 \%)$

2.2.13 Sanitation and epidemic prevention

$(4.37 \pm 0.597,0.14,95 \%)$

3. Professional ability

3.1 Critical thinking ability

3.1.1 Analysis and induction ability

$(4.58 \pm 0.507$

$0.11,100 \%)$

$(4.79 \pm 0.419,0.09,100 \%)$

$(4.68 \pm 0.478,0.10,100 \%)$ 
Primary indicator

$(\mathrm{M} \pm \mathrm{S}, \mathrm{CV}$, Approval rate

$\%)$
Secondary indicator

( $M \pm S, C V$, Approval rate \%)
Third indicator

( $\mathrm{M} \pm \mathrm{S}, \mathrm{CV}$, Approval rate \%)

3.1.2 Clinical decision-making ability

$(4.58 \pm 0.507,0.11,100 \%)$

communication ability

$(4.42 \pm 0.507,0.11,100 \%)$

3.3 Education and consult ability

$(4.05 \pm 0.621,0.15,84 \%)$
3.2 Interpersonal

3.2.1 Effective communication skills

$(4.58 \pm 0.607,0.13,95 \%)$

3.2.2 Interpersonal skills

$(4.47 \pm 0.612,0.14,95 \%)$

3.3.1 Teaching and training ability

$(4.26 \pm 0.562,0.13,95 \%)$

3.3.2 Health education ability

$(4.42 \pm 0.507,0.11,100 \%)$

3.4 Psychological and

humanistic nursing ability

$(4.32 \pm 0.582,0.13,95 \%)$

3.5 Professional development ability

$(4.16 \pm 0.602,0.14,89 \%)$
3.4.1 Psychological nursing ability

$(4.26 \pm 0.562,0.13,95 \%)$

3.4.2 Humanistic nursing ability

$(4.21 \pm 0.631,0.15,89 \%)$

3.5.1 Self-learning ability

$(4.32 \pm 0.478,0.11,100 \%)$

3.5.2 Research Ability

$(3.95 \pm 0.705,0.18,74 \%)$

3.5.3 Actively participate in continuing education and training

$(4.32 \pm 0.582,0.13,95 \%)$

3.5.4 Actively participate in various competitions

$(4 \pm 0.667,0.17,79 \%)$

4.1.1 Ability to formulate and execute plans

$(4.37 \pm 0.496,0.11,100 \%)$ 
Primary indicator

$(\mathrm{M} \pm \mathrm{S}, \mathrm{CV}$, Approval rate

$\%)$
Secondary indicator

( $M \pm S, C V$, Approval rate \%)

4.1.2 System thinking

$(4.05 \pm 0.78,0.19,74 \%)$

$(4.63 \pm 0.496$

$0.11,100 \%)$

\section{Third indicator}

( $M \pm S, C V, A p p r o v a l$ rate \%)
4.2 Organizing

$(4.47 \pm 0.612,0.14,95 \%)$

4.3 Leading

$(4.16 \pm 0.602,0.14,89 \%)$

4.4 Controlling

$(4.42 \pm 0.692,0.16,89 \%)$

5.1 Military quality

$(4.47 \pm 0.612,0.14,95 \%)$

4.2.1 Organization and coordination ability

$(4.11 \pm 0.658,0.16,84 \%)$

4.2.2 Teamwork ability

$(4.26 \pm 0.653,0.15,89 \%)$

4.3.1 Ability to train others

$(4.21 \pm 0.631,0.15,89 \%)$

4.3.2 Exemplary leading role

$(4.32 \pm 0.671,0.16,89 \%)$

4.4.1 Emergency response capacity

$(4.63 \pm 0.496,0.11,100 \%)$

4.4.2 Quality and safety awareness

$(4.42 \pm 0.507,0.11,100 \%)$

5.1.1 Political literacy

$(4.68 \pm 0.478,0.10,100 \%)$

5.1.2 Physical literacy

$(4.74 \pm 0.452,0.10,100 \%)$

5.1.3 Military basics

$(4.47 \pm 0.513,0.11,100 \%)$

5.1.4 Survival in the wild

$(4.74 \pm 0.452,0.10,100 \%)$

5.2 Professional quality

$(4.84 \pm 0.375,0.08,100 \%)$
5.2.1 Professional identity

$(4.63 \pm 0.496,0.11,100 \%)$

5.2.2 Sense of responsibility

$(4.84 \pm 0.375,0.08,100 \%)$ 
Primary indicator

$(\mathrm{M} \pm \mathrm{S}, \mathrm{CV}$, Approval rate

$\%)$
Secondary indicator

( $M \pm S, C V$, Approval rate \%)

5.2.3 Empathy

$(4.42 \pm 0.692,0.16,89 \%)$

5.2.4 Cautiousness

$(4.84 \pm 0.375,0.08,100 \%)$

5.2.5 Professional etiquette and image

$(4.21 \pm 0.713,0.17,84 \%)$

5.3 Personality characteristics

$(3.95 \pm 0.705,0.18,74 \%)$
5.3.1 Determination

$(4.79 \pm 0.419,0.09,100 \%)$

5.3.2 Self-control and stress resistance

$(4.53 \pm 0.513,0.11,100 \%)$

5.3.3 Adaptability and adaptability

$(4.68 \pm 0.478,0.10,100 \%)$

5.3.4 Innovation ability

$(4 \pm 0.745,0.19,74 \%)$

5.3.5 Execution ability

$(4.68 \pm 0.478,0.10,100 \%)$

\section{Discussion}

This study attempted to identify competencies for military nurses in China context through a scoping review to develop the initial framework and through the Delphi process to obtain consensus from a panel of expert. After the second round, the experts reached consensus on 67 of 76 statement. These identified competency statement were grouped into five domains: clinical nursing knowledge and skills, military nursing knowledge and skills, professional ability, management ability, and comprehensive quality.

As shown in Fig. 2, military nurses should possess clinical/military nursing knowledge and skills, which is corresponding to two different kinds of work environment. Military nurses not only provide care to patients in hospitals, but also care for diverse patients during deployment [7]. Military nurses should also possess professional ability and management ability, and this is in line with the diverse responsibilities military nurses shoulder, including playing an important part in management and leadership position [9]. 
The inner layer of the competency framework was comprehensive quality, which are composed by military quality, professional quality, and personality characteristics.

To some extent, the competency framework of military nurses in this study is different from the competency framework of civilian nurses in the past research, such as 6-D Scale, NCS, SECC. Firstly, the competency framework in this study was designed for military nurses, and this framework reflected their dual roles and diverse responsibilities. Secondly, the competency framework in this study was developed based on the Onion Model of competency theory, which not only facilitate to include all the elements of competency model, but also help to clarify different elements of competency model [2]. When compared with the advanced nursing practice pillars for UK military and READI in USA military, it can be found out that the competency framework in this study covered most domains of the above two, such as clinical practice, operational nursing, management, research, education, soldier/survival skills $[9,13]$.

Past research showed that deployment is challenge to military nurses, and they are likely to feel insufficiently prepared during deployment [18]. A full preparation plays an crucial role for military nurses to successfully complete their duties [8]. As shown in Fig. 2, the competency framework in this study was leveled by Patricia Benner's five levels of competency: novice, advanced beginner, competent, proficient and expert [19]. This framework can be used to guide the CBE for different level of military nurses.

Trustworthiness of the Delphi study was ensured by credibility, transferability, confirmability, and dependability [20-21]. In this study, experts with different background within military nursing and medicine were selected to assure credibility. Transferability was assured by developing a competency framework which was generalizable to military hospitals throughout China. Confirmability was confirmed through providing the expert penal with detailed results of each round and feedback of each experts. Dependability was assured by inviting more experts to review the final framework. Furthermore, high response rate was achieved during two rounds.

This review has strengths and limitations. This study aimed to develop a robust competency framework of military nurses which can be used in competency assessment, competency building and personnel recruitment. However, This study has its limitations. Firstly, the methodological of the Delphi study has its own limitations, such as the difficulty of generalising the results to a wider population due to the sample size and the uneven spread of expertise among cultural location [22]. Secondly, we only invited Chinese experts on military medicine and nursing to participate in this study. Before conducting the Delphi study, the competency framework initially was developed through the scoping review to maximize the generalization of results in China to the worldwide. This competency framework may be more suitable for Chinese military nurses, however, it can also can provide a a reference for military nursing in other countries.

\section{Conclusion}

This study developed a competency framework of military nurses through two-phased procedure, which can be a crucial step in implementing CBE among military nurses. This framework can also be used to 
develop a competency measurement tool to assist the regular capacity building and readiness training of this population. Subsequent research should include to develop a valid instrument to measure the competency and design CBE curricula for military nurses. These findings supports the delivery of professional nursing care to promote patient safety in hospitals and assure the fast and scientific rescue during deployment.

\section{Declarations}

\section{Acknowledgements}

None.

\section{Authors' contributions}

HJM, ZC, JT and LY had full access to all of the data in the study and take responsibility for the integrity of the data and the accuracy of the data analysis. HJM, ZC and YL analyzed the data and wrote the manuscript. HJM, JT and YL designed the study and revised the manuscript. All authors read and approved the final manuscript.

\section{Ethics approval and consent to participate}

This study protocol was submitted to the Medical Ethics Committee of Army Medical University in Chongqing, China. The research was approved by the Medical Ethics Committee and determined to be exempt. This study was conducted after obtaining written informed consent from the participants. This study also was carried out in accordance with relevant guidelines and regulations in the Ethical Declarations.

\section{Consent for publication}

Not applicable.

\section{Availability of data and material}

Data are available on request to Yu Luo.

\section{Competing interests}

The authors declare that they have no competing interests.

\section{Disclosure statement}

No potential conflict of interest was reported by the authors.

\section{Funding}


This research is funded by the Military Medical Innovation Project of China under Grant (number18CXZ020).

\section{References}

1. McClelland DC. Testing for competence rather than for "intelligence". Am Psychol. 1973;28(1):1-14.

2. Spencer L, Spencer S. Competence at Work: Model for Superior Performance. New York, John Wiley \& Sons; 1993.

3. Chouhan V, Srivastava S.Understanding Competencies and Competency Modeling - A Literature Survey. IOSR Journal of Business and Management. 2014; 16: 14-22.

4. Frank JR, Snell LS, Cate OT, et al. Competency-based medical education: theory to practice. Med Teach. 2010;32(8):638-645.

5. Keshmiri F, Gandomkar R, Hejri SM, Mohammadi E, Mirzazadeh A. Developing a competency framework for Health Professions Education at doctoral level: The first step toward a competency based education. Med Teach. 2019;41(11):1298-1306.

6. Michaud J, Moss K, Licina D, et al. Militaries and global health: peace, conflict, and disaster response. Lancet. 2019;393(10168):276-286.

7. Kenward G, Marshall S, Irvine K. How much is enough? Using Delphi to explore the clinical-contacttime and return-to-practice needs of military nurses. Nurs Manag. 2017;24(2):20-24.

8. $\mathrm{Ma} \mathrm{H}$, Chihava TN, Fu J, et al. Competencies of military nurse managers: A scoping review and unifying framework. J Nurs Manag. 2020;28(6):1166-1176.

9. Ross MC. Military nursing competencies. Nurs Clin North Am. 2010;45(2):169-177.

10. Meretoja R, Isoaho H, Leino-Kilpi H. Nurse competence scale: development and psychometric testing. J Adv Nurs. 2004;47(2):124-133.

11. Hsu LL, Hsieh SI. Testing of a measurement model for baccalaureate nursing students' selfevaluation of core competencies. J Adv Nurs. 2009;65(11):2454-2463.

12. Liu M, Yin L, Ma E, Lo S, Zeng L. Competency Inventory for Registered Nurses in Macao: instrument validation. J Adv Nurs. 2009;65(4):893-900.

13. Royal PM, Smith MB. A UK Military nurse practitioner on Exercise SAIF SAREEA 3: the first Overseas deployment. BMJ Mil Health. 2020;166(6):425-428.

14. Reineck C, Finstuen K, Connelly LM, Murdock P. Army nurse readiness instrument: psychometric evaluation and field administration. Mil Med. 2001;166(11):931-939.

15. Raghav PR, Kumar D, Bhardwaj P. Experience of Delphi technique in the process of establishing consensus on core competencies. Int J Appl Basic Med Res. 2016;6(3):191-194.

16. Keeney S, Hasson F, McKenna H. The Delphi Technique in Nursing and Health Research. Chichester, Wiley-Blackwell; 2011. 
17. Levac D, Colquhoun H, O'Brien KK. Scoping studies: advancing the methodology. Implement Sci. 2010;5:69.

18. Labrague LJ, Hammad K, Gloe DS, et al. Disaster preparedness among nurses: a systematic review of literature. Int Nurs Rev. 2018;65(1):41-53.

19. Benner P. From novice to expert. Am J Nurs. 1982;82(3):402-407.

20. Hewitt, C. M., Roye, C., \& Gebbie, K. M. Core competency model for the family planning public health nurse. Public Health Nurs. 2014;31:472-479.

21. Zhang X, Meng K, Chen S. Competency framework for specialist critical care nurses: A modified Delphi study. Nurs Crit Care. 2020;25(1):45-52.

22. Fink-Hafner D, Dagen T, Dousak M, Novak M, Hafner-Fink M. Delphi Method: Strengths and Weaknesses. Metodoloski zvezki, 2019; 16 (2): 1-19.

\section{Figures}

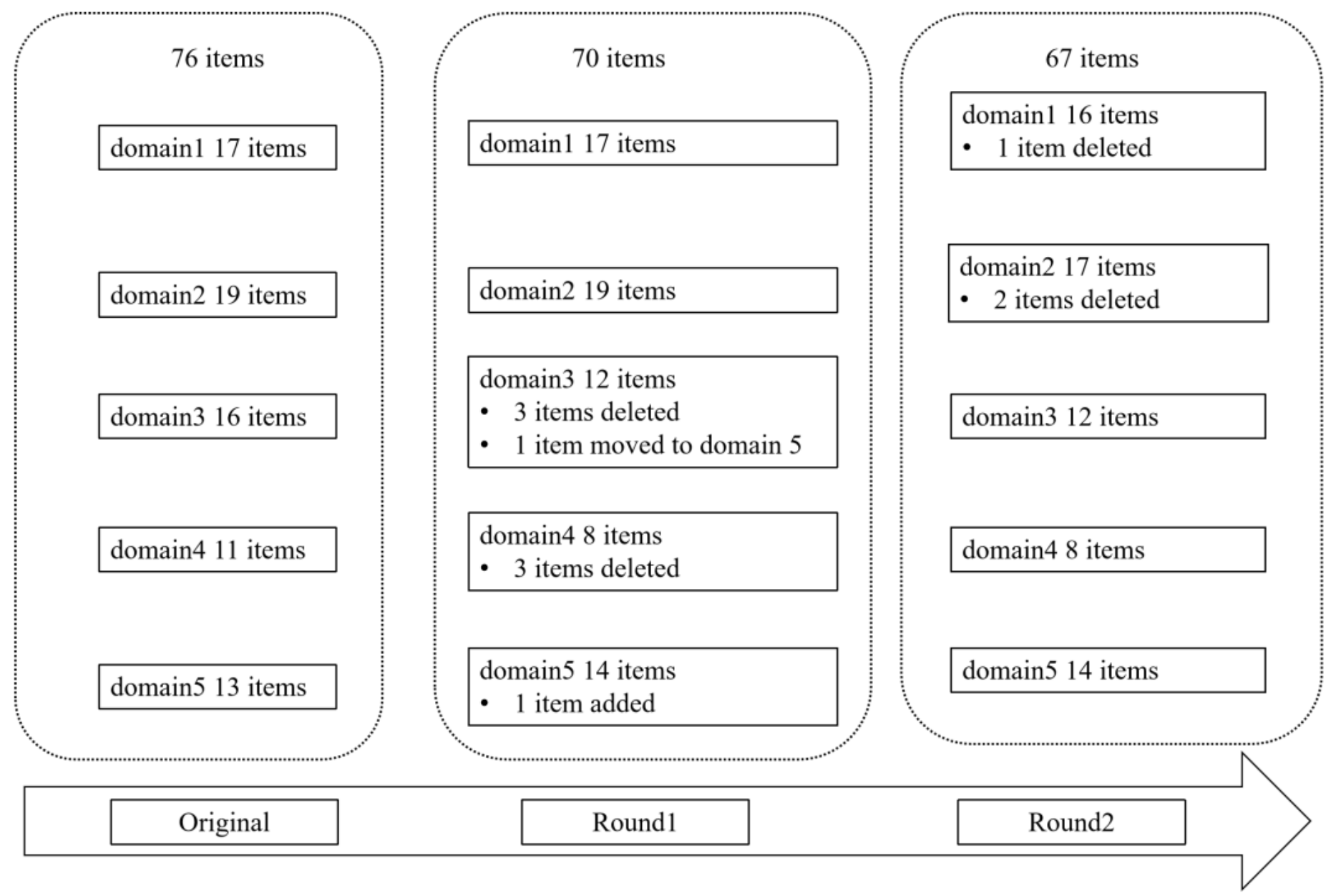

\section{Figure 1}

Flowchart of Delphi process 


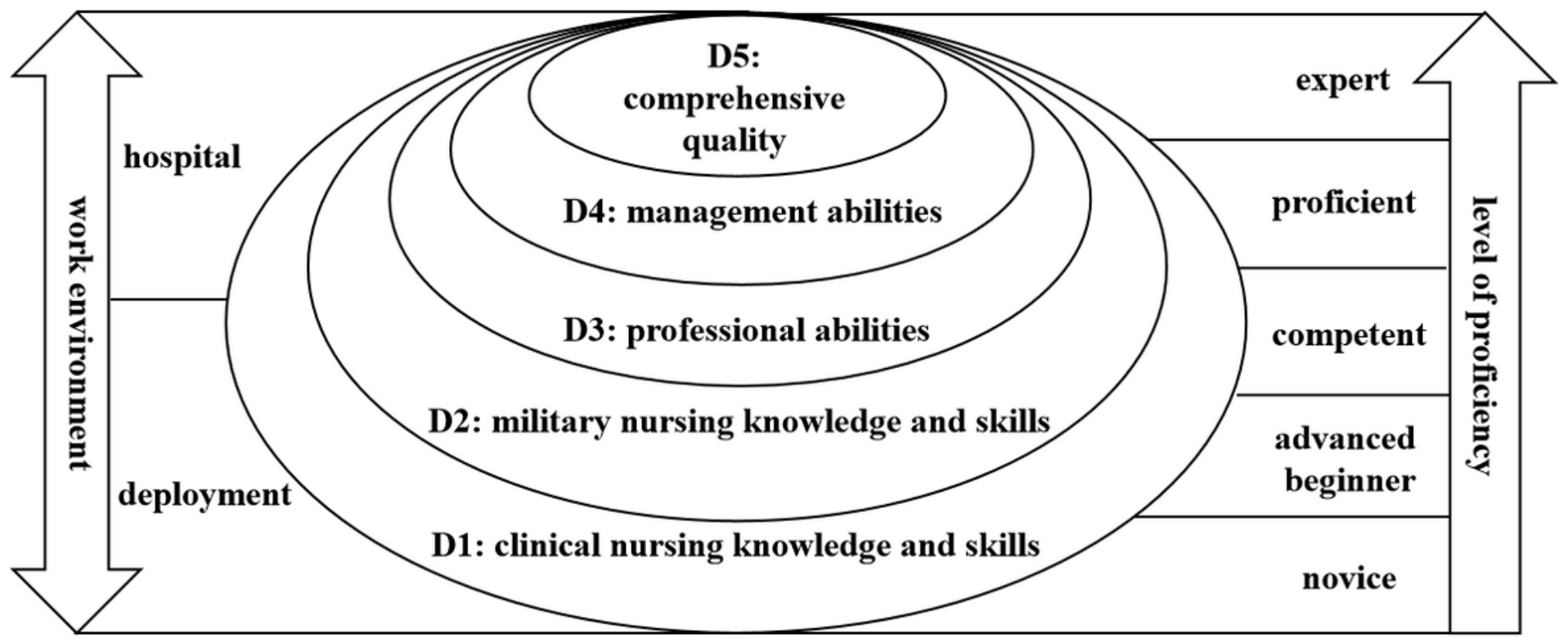

Figure 2

Competency framework for CBE among military nurses 